\title{
Aqueous extract of pomegranate seed attenuates glucocorticoid-induced bone loss and hypercalciuria in mice: A comparative study with alendronate
}

\author{
YAN ZHANG ${ }^{*}$, JIN SHAO*, ZHI WANG, TIEYI YANG, SHUYI LIU, YUE LIU, XINBING FAN and WEIGUANG YE \\ Department of Orthopaedics, Gongli Hospital of Pudong New Area, Shanghai 200135, P.R. China
}

Received July 9, 2015; Accepted April 22, 2016

DOI: $10.3892 /$ ijmm.2016.2622

\begin{abstract}
The present study was performed in order to examine bone loss and calcium homeostasis in mice with glucocorticoid (GC)-induced osteoporosis (GIOP) following treatment with the aqueous extract of pomegranate seed (AE-PS). In addition, a comparative study with alendronate was performed. Biomarkers in the serum and the urine were measured. The tibias, kidney and duodenum were removed in order to measure the levels of bone calcium, protein expression as well as to perform histomorphological analysis of the bone. GC treatment facilitated the induction of hypercalciuria in the mice, and the AE-PS-treated mice exhibited a greater increase in serum calcium and a decrease in urine calcium. The AE-PS reversed the deleterious effects on the trabecular bone induced by DXM and stimulated bone remodeling, including an increase in bone calcium and alkaline phosphatase-b (ALP-b) and a decrease in a the critical bone resorption markers $\mathrm{C}$-terminal telopeptide of type I collagen (CTX) and tartrate-resistant acid phosphatase-5b (TRAP-5b). Hematoxylin and eosin (H\&E) staining revealed the increased disconnections and separation between the growth plate and the trabecular bone network as well as the reduction in the trabecular bone mass of the primary and secondary spongiosa throughout the proximal metaphysis of the tibia in the DXM group. Moreover, the decreased protein expression of transient receptor potential vanilloid (TRPV)5, TRPV6 and calbindin-D9k (CaBP-9k) was reversed by the AE-PS or alendronate supplementation in the kidneys and the duodenum as well as plasma membrane $\mathrm{Ca}^{2+}$-ATPasel (PMCA1) expression in the kidneys of mice with GIOP. There was no marked difference in pharmacological effectiveness between alendronate and the AE-PS. Taken together, these findings suggest that the AE-PS
\end{abstract}

Correspondence to: Dr Tieyi Yang, Department of Orthopaedics, Gongli Hospital of Pudong New Area, 219 Miaopu Road, Shanghai 200135, P.R China

E-mail: orthopaedics_yang@163.com

*Contributed equally

Key words: aqueous extract of pomegranate seed, dexamethasone, hypocalcemia, hypercalciuria, alendronate may be an alternative therapy suitable for use in the management of secondary osteoporosis.

\section{Introduction}

Glucocorticoids (GCs) are used in clinical practice for their antiinflammatory and immunomodulatory effects $(1,2)$. However, the therapeutic use of GCs in the management of immunosuppression following organ transplantation or of inflammatory diseases is always accompanied by substantial adverse outcomes including diabetes and obesity as well as bone loss, which is referred to in this case as GC-induced osteoporosis (GIOP) (3-5). Bone loss induced by GCs occurs early and progresses at a fast rate becoming significant within the first 6 months (6). Previous studies have demonstrated that the long-term administration of GCs resulted in the development of osteoporosis in approximately $50 \%$ of patients with asthma (7). Moreover, clinical studies have shown that low-dose GC inhalatory therapy (8) or high-dose oral GC therapy, particularly with dexamethasone (DXM) (9) causes bone loss in humans. Briefly, the underlying molecular mechanisms responsible for GC-induced bone loss involve a decrease in bone formation directly by inhibiting osteoblasts from producing new bone and an increase in bone resorption by increasing osteoclast activity $(10,11)$. In vitro studies demonstrated that GCs are capable of inducing the apoptosis of osteoblasts and osteocytes $(3,12)$. Several studies have also showed that proliferation, osteogenic differentiation and reactive activity to an osteogenic inductor were reduced in the bone mesenchymal-derived stem cells (BMSCs) of rats with GIOP $(1,13)$. Moreover, prolonged GC use may induce hypercalciuria; the 24-h urinary calcium excretion was significantly increased at day 7 in a study where patients received treatment with $10 \mathrm{mg}$ methylprednisolone daily (14). Notably, the adminstration of GCs to patients with vitamin D insufficiency may lead to hypocalcemia in combination with hypercalciuria and secondary hyperparathyroidism in the absence of hypomagnesemia (15).

Pomegranate [Punica granatum L. (Punicaceae)] is an edible fruit native to the Middle East which has been used extensively in folk medicine for a number of therapeutic purposes $(16,17)$. It has been reported that pomegranate possesses powerful antioxidant activity $(18,19)$ and further studies are warranted into the adjuvant therapeutic applications of pomegranate in human breast cancer (20). Pomegranate seeds (PSs) are known 
to contain the estrogenic compounds, estrone and estradiol, which are chemically identical to those biosynthesized in the human body $(16,17)$. As pomegranate seed oil (PSO) contains phytoestrogens, the hypothesis that PSO is capable of preventing bone loss in postmenopausal women may be true (17). In vivo studies of ovariectomized mice showed that the ovariectomy-induced decrease in bone mineral density (BMD) was normalized by the administration of pomegranate extract (16). Moreover, pomegranate and its derivatives prevented bone loss in a mouse model of postmenopausal osteoporosis through osteoblastic stimulation and osteoclastic inhibition as well as decreasing inflammation and oxidative stress (21). However, the effects of PSO in other experimental animal models, such as the animal model of GIOP, remain largely unknown.

As mentioned above, previous studies have suggested that PS extracts exert a protective effect against bone loss. However, there have been no reports to date in the scientific literature, to the best of our knowledge, that PS extracts protect against hypercalciuria. In light of these observations, we aimed to determine whether PSO may be useful in the treatment of GIOP and hypercalciuria, and to compare the effectiveness of this compound with alendronate. Alendronate is a commonly prescribed bisphosphonate and bisphosphonates are the gold standard treatment for osteoporosis.

\section{Materials and methods}

Animal treatment. Six-week-old male C57BL/6J mice were obtained from the Shanghai Laboratory Animals Center (SLAC; Shanghai, China) and were allowed to acclimate to the environment for 1 week. All experimental procedures were performed in accordance with the Guidelines of the Department of Orthopaedics at Gongli Hospital of Pudong New Area (Shanghai, China) on Animal Care. This study was approved by the Ethics Committee of the Department of Orthopaedics at Gongli Hospital of Pudong New Area. All chemicals and reagents were purchased from Sigma-Aldrich Canada Co., (Oakville, Ontario, Canada), except where noted otherwise.

The mice were randomly divided into four groups: i) vehicle group mice $(n=8)$ were injected intramuscularly with saline instead of DXM as controls; ii) the mice in the DXM group were injected intramuscularly with $5 \mathrm{mg} / \mathrm{kg}$ body weight DXM three times a week for 12 weeks $(n=8)$; iii) the mice in the ALN group received alendronate orally at a dose of $0.1 \mathrm{mg} / \mathrm{kg} / \mathrm{day}$ in combination with DXM for 12 weeks $(n=8)$; and iv) the mice in the PS group received daily drinks of aqueous extract of pomegranate seed (AE-PS) in combination with DXM for 12 weeks $(n=8)$. Pomegranate seeds $(100 \mathrm{~g})$ were chopped in a mortar and extracted in water $(1,000 \mathrm{ml})$ by means of agitation for $10 \mathrm{~min}$ at room temperature. Supernatants were filtered out and the filtrates were given to the mice daily as drinking water. The pomegranates were purchased from the Chinese herbal medicine market in Nanjing (Jiangsu, China).

Chemistry of serum, urine and bone calcium content. The concentrations of calcium $(\mathrm{Ca})$ and testosterone in the serum as well as creatinine $(\mathrm{Cr})$ in the urine were measured by ELISA using a microplate reader (BioTek, Winooski, VT, USA). Serum was collected by cardiac exsanguination under light ether anesthesia. Urine ( $24 \mathrm{~h}$ ) was collected from the mice using metabolic cages. The level of urine $\mathrm{Ca}$ was corrected by the concentration of urine $\mathrm{Cr}$. The serum levels of bone-specific alkaline phosphatase (ALP-b), testosterone, tartrate-resistant acid phosphatase (TRAP)-5b, C-terminal telopeptide of type I collagen (CTX) and osteocalcin were detected using a rat bioactive parathyroid hormone (PTH) enzyme-linked immunosorbent assay (ELISA; Immutopics, Inc., San Clemente, CA, USA) with an ELISA reader (MD SpectraMax M5; Molecular Devices, LLC, Sunnyvale, CA, USA).

The tibias were incinerated at $800^{\circ} \mathrm{C}$ for $6 \mathrm{~h}$ and the ash weighed. Ten milligrams of bone ash was then dissolved in $1 \mathrm{ml}$ of $37 \% \mathrm{HCl}$ and diluted with Millin-Q water. The $\mathrm{Ca}$ content was determined using the same kits as those used for the serum and urine calcium assays (Biosino, Beijing, China).

Bone histomorphology. Mice were sacrificed by cardiac exsanguination under light ether anesthesia. After cardiac exsanguination, the tibias were collected with all soft tissue removed and stored at $-80^{\circ} \mathrm{C}$. A total of 8 tibias were used for histomorphological analysis. The right tibia was used for histomorphological analysis, and the left tibia was used for the RT-PCR and western blot analysis ( $n=8$ in each group). The tibias were decalcified in $0.5 \mathrm{M}$ ethylenediaminetetraacetic acid (EDTA) ( $\mathrm{pH}$ 8.0), followed by dehydration through a graded series of ethanol solutions and then embedded in paraffin according to standard histological procedures (22). Sections, $5 \mu \mathrm{m}$ in thickness, were cut and stained with hematoxylin and eosin (H\&E; Xinfan, Shanghai, China), and visualized under a microscope (Leica DM 2500; Leica Microsystems GmbH, Wetzlar, Germany).

TRAP staining was used for the identification of osteoclasts according to the manufacturer's instructions (387-A; Sigma-Aldrich, St. Louis, MO, USA). The number of TRAP-positive osteoclasts was counted to quantify the number of osteoclasts below the growth plates in the distal metaphysis of the femur. The assays were scored by averaging the number of osteoclasts per low-power field in at least four fields per slide, and visualized under a microscope (Leica DM 2500; Leica Microsystems GmbH).

Reverse transcription-polymerase chain reaction (RT-PCR). After cardiac exsanguination, the kidneys were collected with all soft tissue removed and stored at $-80^{\circ} \mathrm{C}$. The kidneys of each animal were crushed under liquid nitrogen conditions and RNA extraction was performed using TRIzol according to the manufacturer's instructions (Invitrogen, Carlsbad, CA, USA). The synthesis of cDNAs was performed by reverse transcription reactions with $1 \mu \mathrm{g}$ of total RNA using Moloney murine leukemia virus reverse transcriptase (Invitrogen) with oligo(dT) 15 primers (Fermentas, Vilnius, Lithuania) as described by the manufacturer's instructions. The first strand cDNAs served as the template for the regular PCR performed using a Real-Time PCR System (ABI 7300; Applied Biosystems Life Technologies, Foster City, CA, USA). Glyceraldehyde 3-phosphate dehydrogenase (GAPDH) was used as an internal control to normalize the data to determine the relative expression of the target genes. The reaction conditions were set according to the kit instructions. PCR was performed with the following primers: calcium sensing receptor (CaSR), forward, 5'-TAGGCATTCTGTAATAGCT-3' 

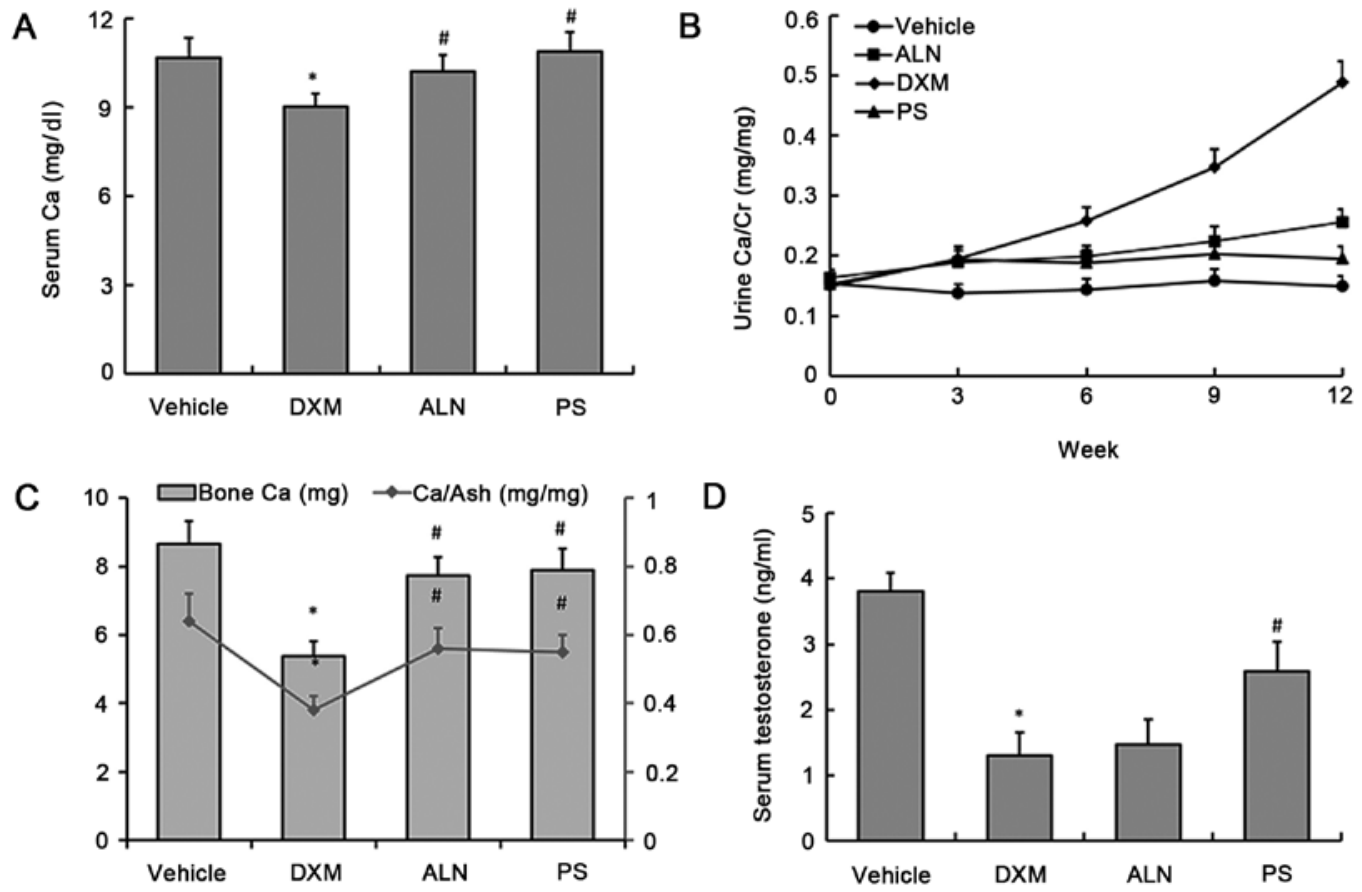

Figure 1. Calcium levels in serum, urine and tibias and serum testosterone levels. (A) Serum calcium (Ca) levels, (B) Ca/creatinine (Cr) ratios in urine and (C) Ca concentrations and $\mathrm{Ca} / \mathrm{Ash}$ ratios in tibias. (D) Analysis of serum testosterone levels by ELISA. Values are expressed as the means \pm SEM, $\mathrm{n}=8 \mathrm{in}$ each group. "P<0.05 versus vehicle group; ${ }^{*} \mathrm{P}<0.05$, versus dexamethasone (DXM) group. Vehicle, vehicle group ( $\mathrm{n}=8$ ); DXM group, mice were injected intramuscularly with $5 \mathrm{mg} / \mathrm{kg}$ body weight DXM three times/week for 12 weeks $(\mathrm{n}=8)$; ALN group, mice received alendronate orally at a dose of $0.1 \mathrm{mg} / \mathrm{kg} / \mathrm{day}$ in combination with DXM for 12 weeks $(\mathrm{n}=8)$; pomegranate seed (PS) group, mice received daily drinks of aqueous extract of pomegranate seed (AE-PS) in combination with DXM for 12 weeks $(\mathrm{n}=8)$.

and reverse, 5'-CTGGGCTGCTCAGTCGG-3'. The PCR conditions were as follows: denaturation of cDNA at $95^{\circ} \mathrm{C}$ for $3 \mathrm{~min}$, denaturation at $95^{\circ} \mathrm{C}$ for $15 \mathrm{sec}$; annealing $56^{\circ} \mathrm{C}$ for $20 \mathrm{sec}$; extension at $72^{\circ} \mathrm{C}$ for $20 \mathrm{sec}$. The amplification cycle number was 40 for the target gene.

Western blot analysis. The tibias, kidney and duodenum were homogenized and extracted in NP-40 buffer, followed by $5-10$ min of boiling and centrifugation $\left(10,000 \times \mathrm{g}\right.$, at $\left.4^{\circ} \mathrm{C}\right)$ in order to obtain the supernatant. The samples containing $50 \mu \mathrm{g}$ of protein were separated on $10 \%$ SDS-PAGE gel, transferred to nitrocellulose membranes (Bio-Rad Laboratories, Inc., Hercules, CA, USA). After saturation with $5 \%(\mathrm{w} / \mathrm{v})$ non-fat dry milk in Tris-buffered saline (TBS) and $0.1 \%$ (w/v) Tween-20 (TBST), the membranes were incubated with the following antibodies: transient receptor potential vanilloid (TRPV)5 (sc-398345; 1:500), TRPV6 (sc-28763; 1:500), osteoprotegerin (OPG; sc-8468; 1:1,000) and receptor activator of nuclear factor- $\kappa \mathrm{B}$ ligand (RANKL; sc-7628; 1:2,000), CaSR (sc-32181; 1:500), calbindin-D9k (CaBP-9k; sc-367381; 1:500), plasma membrane $\mathrm{Ca}^{2+}$-ATPasel (PMCA1; sc-16488; 1:500) (all from Santa Cruz Biotechnology, Inc., Santa Cruz, CA, USA), overnight at $4^{\circ} \mathrm{C}$. After three washes with TBST, the membranes were incubated with secondary immunoglobulins (Igs) conjugated to IRDye 800CW Infrared Dye (LI-COR Biosciences, Lincoln, NE, USA), including donkey anti-goat IgG and donkey anti-mouse $\operatorname{IgG}$, at a dilution of 1:10,0001:20,000. After a $1-\mathrm{h}$ incubation at $37^{\circ} \mathrm{C}$, the membranes were washed three times with TBST. The blots were visualized using the Odyssey Infrared Imaging system (LI-COR Biosciences). Signals were densitometrically assessed (Odyssey Application Software version 3.0; LI-COR Biosciences) and normalized to the GAPDH signals to correct for unequal loading using the mouse monoclonal anti-GAPDH antibody (AP0063; 1:20,000; Bioworld Technology, Inc., St. Louis Park, MN, USA).

Statistical analysis. All data are expressed as the means \pm standard error of mean (SEM). The statistical analyses were performed using the SPSS 13.0 statistical software package (SPSS Inc., Chicago, IL, USA). One-way analysis of variance (ANOVA) was used to perform comparisons among the different groups, and $\mathrm{P}<0.05$ was considered to indicate a statistically significant difference.

\section{Results}

Chemistry of serum, urine and tibias. Following DXM administration for 12 weeks, the GC-treated animals exhibited significant decreases in serum calcium $(9.02 \pm 0.44 \mathrm{mg} / \mathrm{dl})$, bone calcium content $(5.38 \pm 0.43 \mathrm{mg})$ and calcium/bone ash $(0.38 \pm 0.04)$ (Fig. $1 \mathrm{~A}$ and C). Urine calcium levels were comparable among the four experimental groups. At 12 weeks, when comparing the urine calcium levels between the vehicle and the DXM groups, we observed that calcium secretion in the urine continually increased as the duration of DXM treatment increased (Fig. 1B). At the end of the treatment period, the AE-PS and alendronate increased serum calcium levels, bone calcium content and calcium/bone ash, and hypercalciuria was markedly inhibited in the mice with GIOP (Fig. 1A-C). There was no significant difference observed between the two treatment groups. Additionally, the results showed that the serum testosterone level in the DXM group was significantly decreased as compared with that of the control group; however, AE-PS treatment alone, 

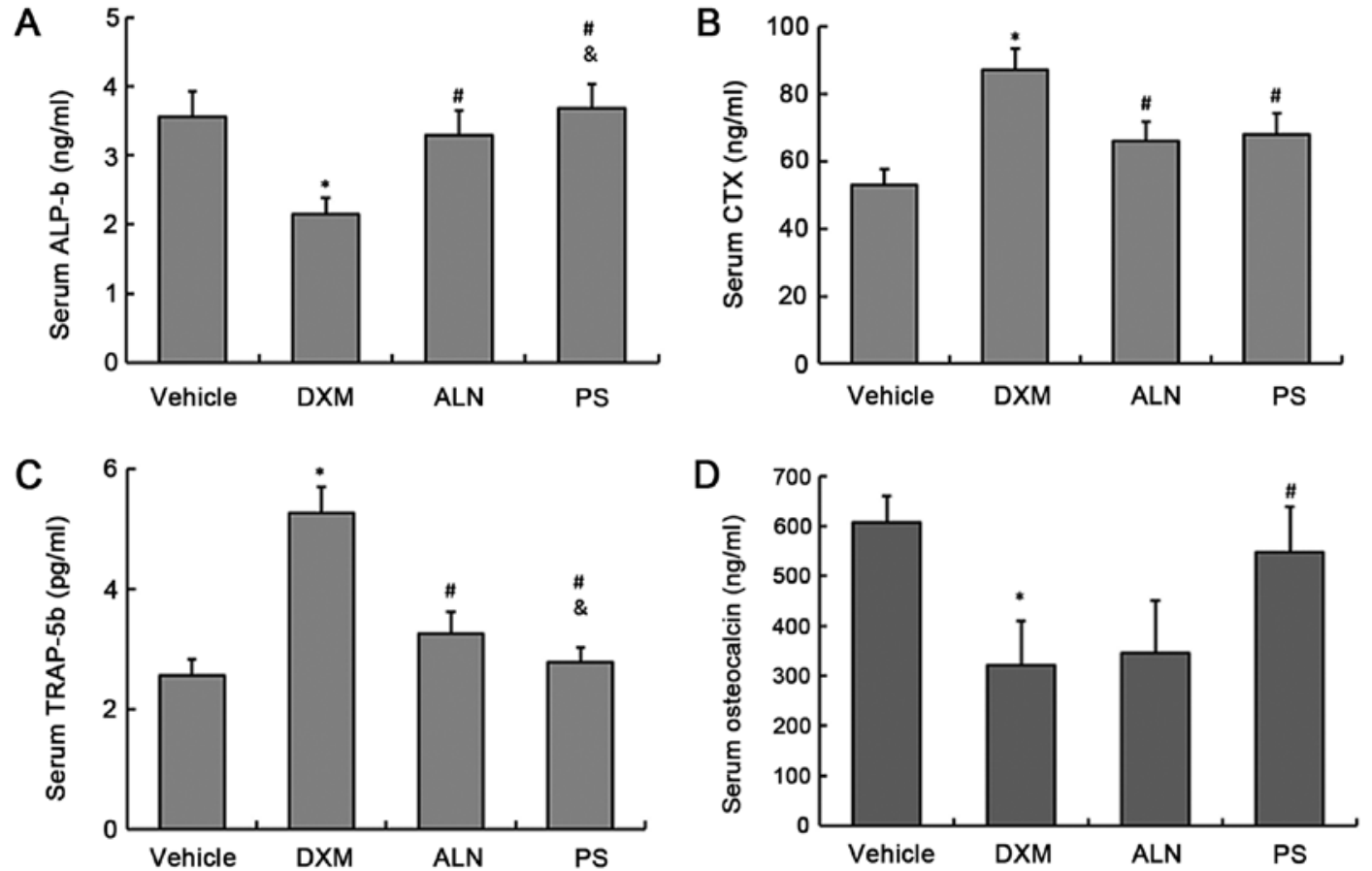

Figure 2. Changes in the serum levels of biomarkers of bone metabolism. Analysis of (A) bone-specific alkaline phosphatase (ALP-b), (B) C-terminal telopeptide of type I collagen (CTX), (C) tartrate-resistant acid phosphatase-5b (TRAP-5b) and (D) osteocalcin was measured by ELISA. Values are expressed as the means $\pm \mathrm{SEM}, \mathrm{n}=8$ in each group. ${ }^{*} \mathrm{P}<0.05$, versus vehicle group; ${ }^{*} \mathrm{P}<0.05$, versus dexamethasone (DXM) group; and ${ }^{\text {\& }} \mathrm{P}<0.05$ versus ALN group. Vehicle, vehicle group ( $\mathrm{n}=8)$; DXM group, mice were injected intramuscularly with $5 \mathrm{mg} / \mathrm{kg}$ body weight DXM three times/week for 12 weeks ( $\mathrm{n}=8$ ); ALN group, mice received alendronate orally at a dose of $0.1 \mathrm{mg} / \mathrm{kg} /$ day in combination with DXM for 12 weeks $(\mathrm{n}=8)$; pomegranate seed (PS) group, mice received daily drinks of aqueous extract of pomegranate seed (AE-PS) in combination with DXM for 12 weeks $(n=8)$.

A
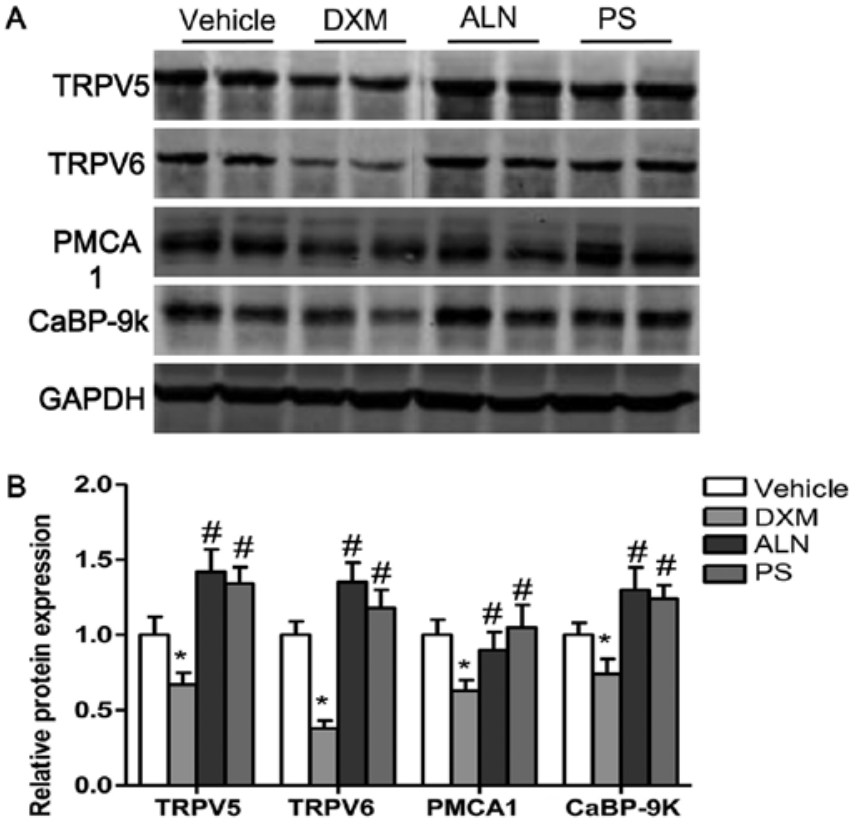

Figure 3. Expression of calcium transport proteins in the kidney. (A and B) The protein levels of calcium transporters [transient receptor potential vanilloid (TRPV)5, TRPV6, calbindin-D9k (CaBP-9k) and plasma membrane $\mathrm{Ca}^{2+}$-ATPase1 (PMCA1)] were measured in the kidney. Values are expressed as the means $\pm \mathrm{SEM}, \mathrm{n}=8$ in each group. ${ }^{*} \mathrm{P}<0.05$ versus vehicle group; ${ }^{~} \mathrm{P}<0.05$ versus dexamethasone (DXM) group. Vehicle, vehicle group $(\mathrm{n}=8)$; DXM group, mice were injected intramuscularly with $5 \mathrm{mg} / \mathrm{kg}$ body weight DXM three times/week for 12 weeks $(\mathrm{n}=8)$; ALN group, mice received alendronate orally at a dose of $0.1 \mathrm{mg} / \mathrm{kg} /$ day in combination with DXM for 12 weeks $(\mathrm{n}=8)$; pomegranate seed (PS) group, mice received daily drinks of aqueous extract of pomegranate seed (AE-PS) in combination with DXM for 12 weeks $(n=8)$. not alendronate, was capable of reversing DXM-induced testosterone deficiency (Fig. 1D).

The serum concentrations of the bone turnover markers, TRAP-5b and CTX as a bone resorption markers and ALP-b and osteocalcin as a bone formation markers, were determined. The results showed that the serum levels of TRAP-5b and CTX in the DXM group were significantly increased, and the serum levels of ALP-b and osteocalcin were significantly decreased when compared with those of the control group (Fig. 2A-D). The AE-PS and alendronate significantly decreased the serum levels of TRAP-5b and CTX, and increased ALP-b and osteocalcin serum levels. However, ANOVA analysis revealed that the AE-PS significantly reduced TRAP-5b levels and raised ALP-b levels when compared with alendronate. There was no significant difference in the serum CTX levels between the two treatment groups (Fig. 2A-D).

Expression of calcium transport proteins in the kidney and in the duodenum. To examine the mechanism responsible for the decreased serum calcium levels and the increased urine calcium concentrations in the DXM-treated mice, we analyzed the expression levels of calcium transport proteins in the kidney and in the duodenum. The expression of two calcium influx channels (TRPV5 and TRPV6), a reflux channel (PMCA1), and an intracellular calcium buffering protein (CaBP-9k) in the duodenum and in the kidney was examined. The protein levels of TRPV5, TRPV6, PMCA1 and CaBP-9k in the kidney were decreased by DXM treatment; however, the decreases in TRPV5, TRPV6, PMCA1 and CaBP-9k protein expression in the kidneys of mice with GIOP were reversed by the AE-PS or alendronate 
A
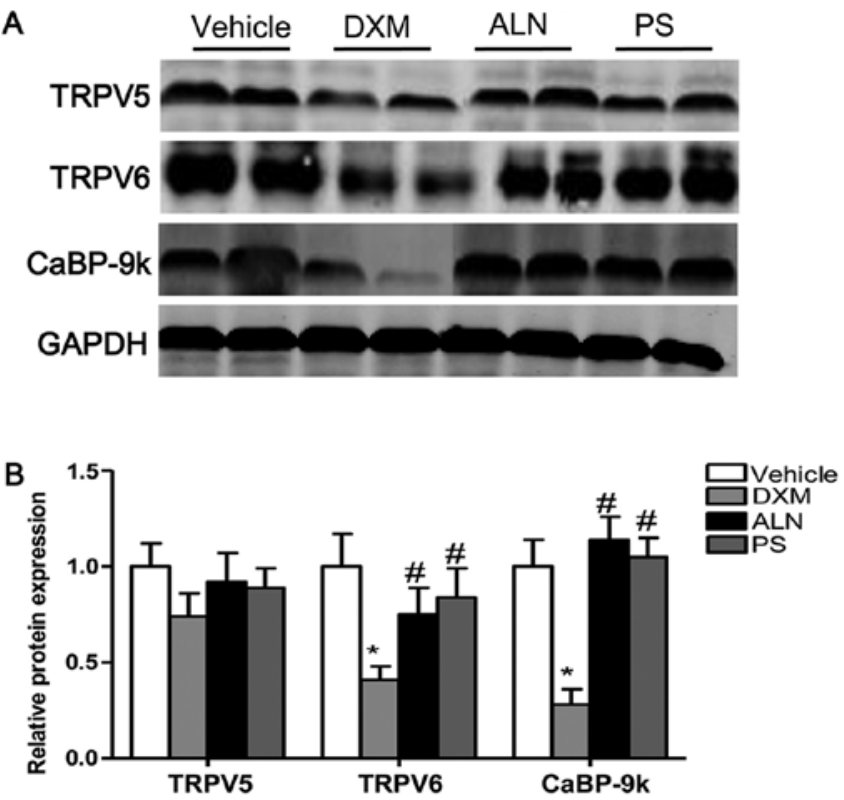

Figure 4. Expression of calcium transport proteins in the duodenum. (A and B) The protein expression of calcium transporters [transient receptor potential vanilloid (TRPV)5, TRPV6, calbindin-D9k (CaBP-9k)] was measured in the duodenum. Values are expressed as the means \pm SEM, $\mathrm{n}=8$ in each group. ${ }^{*} \mathrm{P}<0.05$ versus vehicle group; ${ }^{~} \mathrm{P}<0.05$ versus dexamethasone (DXM) group. Vehicle, vehicle group ( $\mathrm{n}=8)$; DXM group, mice were injected intramuscularly with $5 \mathrm{mg} / \mathrm{kg}$ body weight DXM three times/week for 12 weeks ( $\mathrm{n}=8)$; ALN group, mice received alendronate orally at a dose of $0.1 \mathrm{mg} / \mathrm{kg} / \mathrm{day}$ in combination with DXM for 12 weeks $(\mathrm{n}=8)$; pomegranate seed (PS) group, mice received daily drinks of aqueous extract of pomegranate seed (AE-PS) in combination with DXM for 12 weeks $(n=8)$.

supplementation (Fig. 3A and B). Moreover, the protein levels of TRPV6 and CaBP-9k were significantly decreased by DXM in the duodenum. The AE-PS and alendronate upregulated the protein expression of TRPV6 and CaBP-9k in the duodenum as compared with that in the DXM-treated groups (Fig. 4A and B). There was no significant difference observed between the two treatment groups. The mRNA and protein expression of renal CaSR was increased in the mice with GIOP as compared with the expression levels in the untreated mice. Notably, treatment with the AE-PS significantly downregulated the mRNA expression of CaSR as well as the protein expression of CaSR in the kidneys of mice with GIOP (Fig. 5A-C). The results of western blot analyses revealed that the AE-PS reversed GIOP more effectively than alendronate, although both treatments exerted marked beneficial effects.

TRAP staining and protein expression of OPG/RANKL. TRAP staining revealed that very few osteoclasts were identified in the trabecular bone area below the growth plate in the vehicle group, whereas the number of osteoclasts were significantly increased in this area in the DXM group (Fig. 6A). The treatment of the mice with GIOP with the AE-PS or alendronate significantly decreased the number of osteoclasts (Fig. 6A). As the maturation and formation of osteoclasts are mainly regulated by the balance between extracellular OPG and RANKL levels, the ratio of OPG/RANKL determines the number of matured osteoclasts. Consistent with the TRAP staining results, the results of western blot analysis revealed that the expression of OPG was significantly decreased whereas the expression of RANKL was significantly increased in the mice treated with
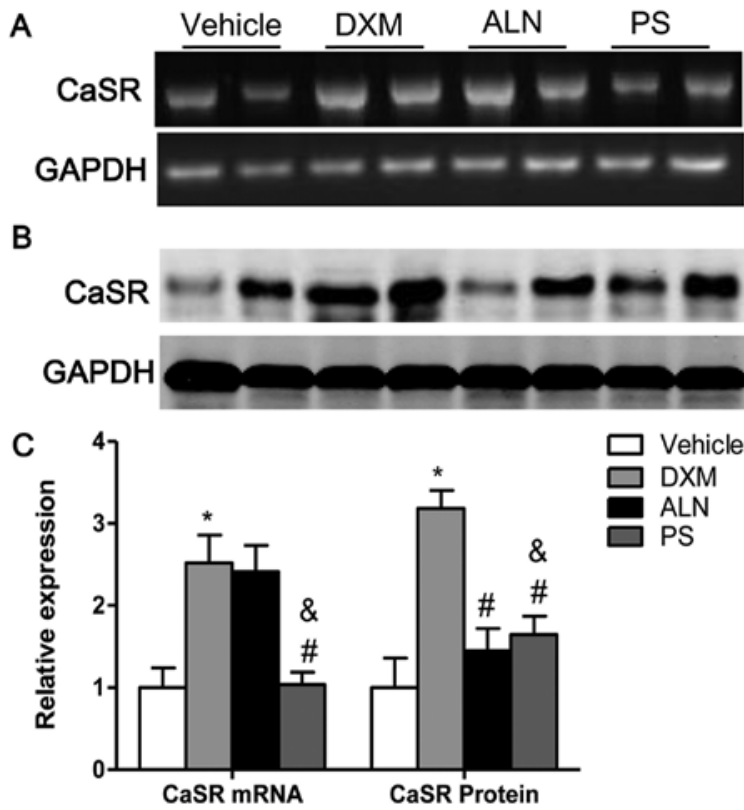

Figure 5. Expression of calcium-sensing receptor (CaSR) in kidney. (A) RT-PCR and (B) western blot analysis of CaSR expression. (C) Densitometric quantification of CaSR using RT-PCR and western blot analysis. Values are expressed as the means $\pm \mathrm{SEM}, \mathrm{n}=8$ in each group ${ }^{*} \mathrm{P}<0.05$ versus vehicle group; ${ }^{\text {}} \mathrm{P}<0.05$ versus dexamethasone (DXM) group; and ${ }^{\circledR} \mathrm{P}<0.05$ versus ALN group. Vehicle, vehicle group $(\mathrm{n}=8)$; DXM group, mice were injected intramuscularly with $5 \mathrm{mg} / \mathrm{kg}$ body weight DXM three times/week for 12 weeks ( $n=8)$; ALN group, mice received alendronate orally at a dose of $0.1 \mathrm{mg} / \mathrm{kg} /$ day in combination with DXM for 12 weeks $(\mathrm{n}=8)$; pomegranate seed (PS) group, mice received daily drinks of aqueous extract of pomegranate seed (AE-PS) in combination with DXM for 12 weeks $(n=8)$.

DXM as compared with the control groups (Fig. 6B and C). The treatment of the DXM group with the AE-PS or alendronate significantly elevated the expression of OPG and suppressed the expression of RANKL (Fig. 6B and C). There was no marked difference between the two treatment groups.

Bone histomorphology and protein expression of calcium transport protein in bone. Histological analysis of trabecular bone in the proximal metaphysis of the mice was performed using the H\&E stain. The histology of trabecular bone near to the growth plate was markedly different in the four experimental groups. $\mathrm{H} \& \mathrm{E}$ staining revealed the increased disconnections and separation between the growth plate and the trabecular bone network as well as the reduction in trabecular bone mass of primary and secondary spongiosa throughout the proximal metaphysis of tibia in the DXM group. Notably, the AE-PS and alendronate reversed the deleterious effects on the trabecular bone induced by DXM and stimulated bone remodeling (Fig. 7A). Histological staining showed that the AE-PS exerted greater effects on bone structure compared with alendronate. Notably, the protein expression of CaSR was increased in the tibias of mice with GIOP compared with those of the untreated mice; however, AE-PS treatment significantly downregulated the protein expression of CaSR in the tibias of the mice with GIOP (Fig. 7B and C). By contrast, the protein expression of CaBP-9k in the tibias of mice with GIOP was decreased compared with those of the untreated mice. The administration of the AE-PS to the mice with GIOP significantly upregulated the protein expression of $\mathrm{CaBP}-9 \mathrm{k}$ in the tibias (Fig. 7B and C). 


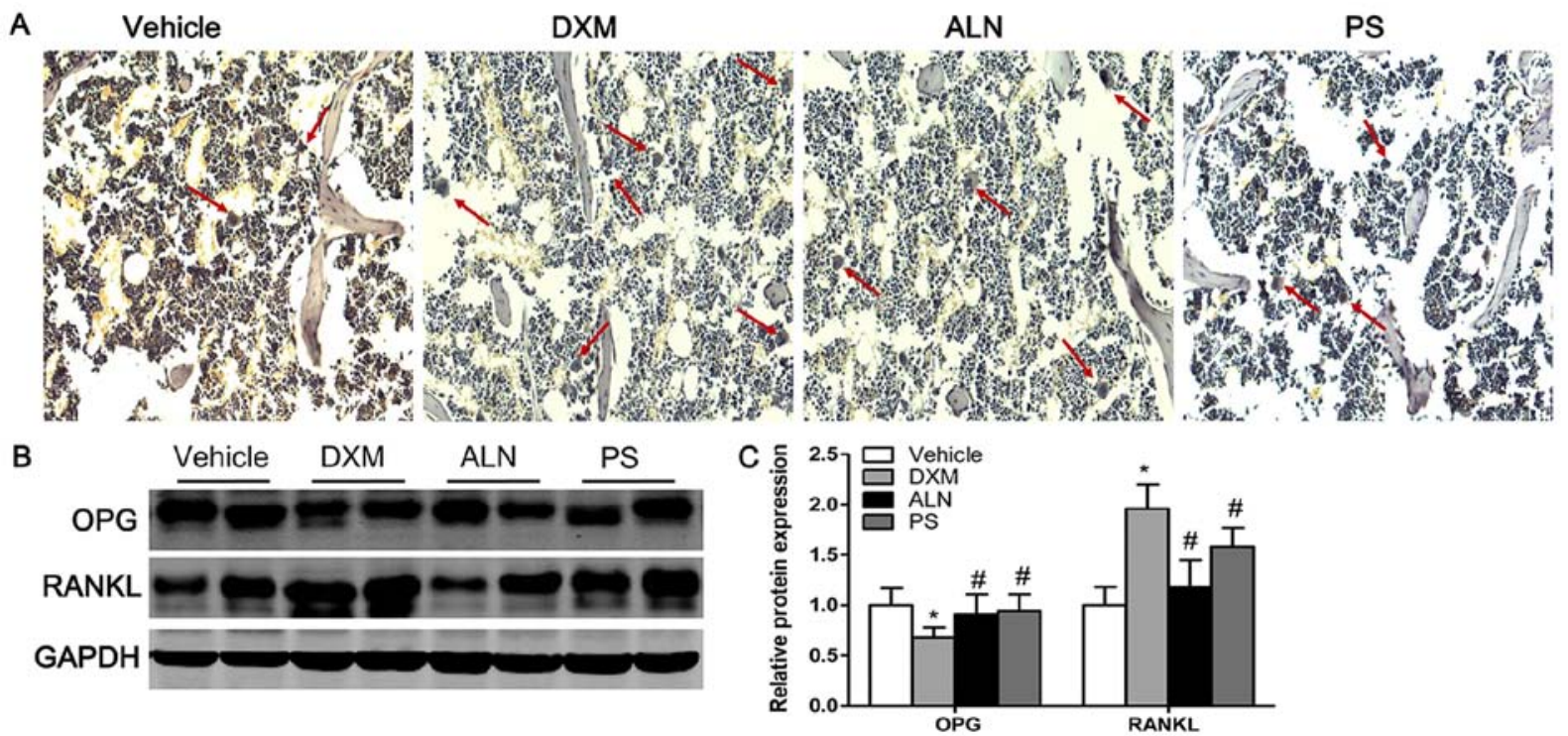

Figure 6. Tartrate-resistant acid phosphatase (TRAP) staining and the protein expression of osteoprotegerin (OPG)/receptor activator of nuclear factor- $\mathrm{KB}$ ligand (RANKL). (A) TRAP staining of the proximal metaphysis of the tibias. Trabecular bone zone and the number of osteoclasts per low-power field (LPF) are shown by the red arrows (magnification, x200). (B) Determination of the protein expression of OPG and RANKL in the tibias of mice. (C) Densitometric quantification of OPG and RANKL expression. Values are expressed as the means $\pm \mathrm{SEM}, \mathrm{n}=8$ in each group. ${ }^{*} \mathrm{P}<0.05$ versus vehicle group; ${ }^{*} \mathrm{P}<0.05$ versus dexamethasone (DXM) group. Vehicle, vehicle group (n=8); DXM group, mice were injected intramuscularly with $5 \mathrm{mg} / \mathrm{kg}$ body weight DXM three times/week for 12 weeks $(n=8)$; ALN group, mice received alendronate orally at a dose of $0.1 \mathrm{mg} / \mathrm{kg} /$ day in combination with DXM for 12 weeks ( $\mathrm{n}=8$ ); pomegranate seed (PS) group, mice received daily drinks of aqueous extract of pomegranate seed (AE-PS) in combination with DXM for 12 weeks (n=8).

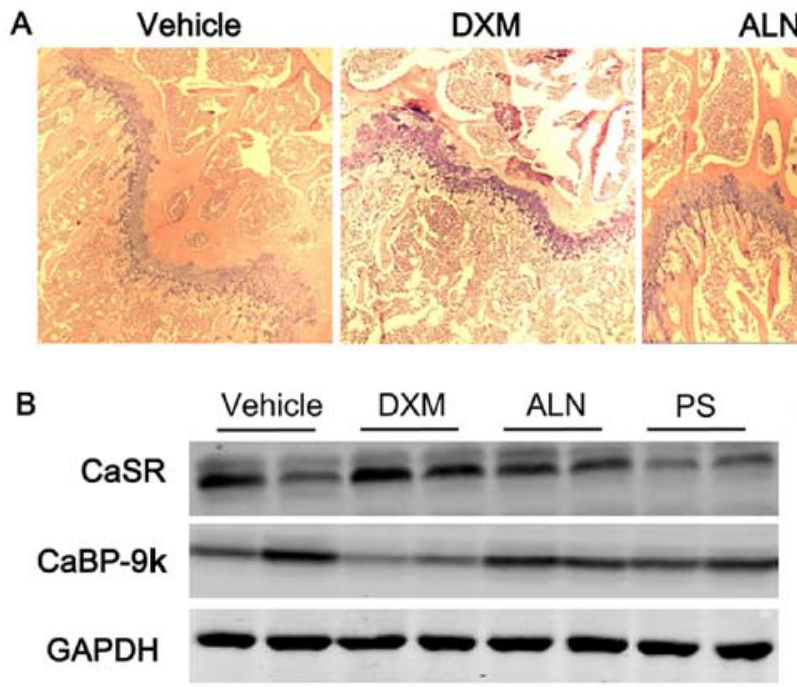

Figure 7. Hematoxylin and eosin (H\&E) staining of the tibias and calcium transport protein expression. (A) H\&E staining of the proximal metaphysis of the tibias. Trabecular bone zone near to the growth plate is shown (magnification, x50). (B) The protein expression of calcium-sensing receptor (CaSR) and calbindin-D9k (CaBP-9k) were performed in the tibias of mice. (C) Densitometric quantification of CaSR and CaBP-9k. Values are expressed as the means \pm SEM, $\mathrm{n}=8$ in each group. ${ }^{*} \mathrm{P}<0.05$ versus vehicle group; ${ }^{*} \mathrm{P}<0.05$ versus dexamethasone (DXM) group; and ${ }^{\&} \mathrm{P}<0.05$ versus $\mathrm{ALN}$ group. Vehicle, vehicle group ( $\mathrm{n}=8$ ); DXM group, mice were injected intramuscularly with $5 \mathrm{mg} / \mathrm{kg}$ body weight DXM three times/week for $12 \mathrm{weeks}$ ( $\mathrm{n}=8$ ); ALN group, mice received alendronate orally at a dose of $0.1 \mathrm{mg} / \mathrm{kg} /$ day in combination with DXM for 12 weeks $(\mathrm{n}=8)$; pomegranate seed (PS) group, mice received daily drinks of aqueous extract of pomegranate seed (AE-PS) in combination with DXM for 12 weeks $(n=8)$.

\section{Discussion}

An increasing amount of evidence suggests a role for the extracts of PS or pomegranate juice in the treatment of postmenopausal bone loss in rodents $(16,17,21,23,24)$. Proof of efficacy, however, in the treatment of GIOP in comparison with currently available treatments remains lacking. In order to clarify this issue, we examined the effects of the AE-PS and compared them with the effects of alendronate in an experimental mouse model of GIOP.

GCs are the mainstay of treatment of many rheumatic diseases and are also an important cause of secondary osteoporosis (25). Rapid loss of BMD with GC administration is greatest in the first year of therapy and may be as high as $30 \%$ or more in 
the first 3-6 months depending on the dose (26). GCs are thought to directly affect the differentiation and activity of osteoblasts and osteocytes. In vitro studies have revealed that DEX induces cytotoxicity and apoptotic cell death in osteoblastic cells and increases the life span of osteoclastic cells, and the apoptosis of osteoblasts is demonstrated by the decrease in the sub-G1 cell population $(27,28)$. In vivo studies demonstrated that, in contrast to the non-treated rabbits or mice, the DEX-injected subjects exhibited the typical features of GIOP as shown by the measurement of the basic biomechanical parameters, including reductions in $\mathrm{BMD}$, and the increased disconnections and separation of the trabecular bone network $(29,30)$. It has been found that these pathological changes in bone metabolism correlate with disturbances of calcium homeostasis (31). As expected, DEX significantly upregulated the urine calcium concentration and downregulated the levels of serum calcium in the mice. Consequently, this led to marked deterioration of the trabecular bone at the proximal metaphysis of the tibia as shown by $\mathrm{H} \& \mathrm{E}$ staining. By contrast, contradictory findings have been demonstrated in premature infants, and DEX exerted no significant effect on the urinary excretion of calcium, although DEX treatment may increase the risk of osteopenia by enhancing phosphate excretion $(32,33)$.

In the present study, the administration of GC injections successfully led to deleterious effects on the bone. The GC-induced increase in bone resorption was confirmed by the increased serum levels of TRAP-5b and CTX, and the decreased serum level of ALP-b. Results from previous studies suggested that the osteoprotective effect of PS or pomegranate juice in the treatment of postmenopausal bone loss resulted from the suppression of bone absorption $(16,17,21)$. In ovariectomized mice, the bone volume and the trabecular number were significantly increased and the trabecular separation was decreased in the pomegranate-treated group; some histological bone formation/resorption parameters were significantly increased by ovariectomy and these were normalized by administration of the pomegranate extract; these changes suggested that the pomegranate extract inhibited ovariectomy-induced bone loss (16).

To elucidate the underlying mechanism involved in the regulatory effects of the AE-PS on calcium metabolism, the expression of active calcium transport proteins in the duodenum and the kidney were measured as it has been demonstrated previously that the extracellular calcium concentration is regulated by the concerted actions of the intestine (intestinal absorption), the kidney (renal re-absorption) and the exchange of calcium to and from bone $(34,35)$. Active calcium transport in the duodenum and the kidney occurs in three stages: calcium entry through epithelial calcium channels (TRPV5 and TRPV6), buffering and/or transporting by CaBP-9k and CaBP-28k, and extrusion through PMCA1b (36). Thus, the expression of the above-mentioned targets was determined in the present study. The results showed that the protein expression of TRPV5, TRPV6 and CaBP-9k was significantly decreased in the duodenum and the kidney, as well as PMCA1 expression in the kidney, in the mice with GIOP; however, the decrease in the protein expression in the kidney and duodenum of the mice with GIOP was reversed by the administration of the AE-PS or alendronate. The calcium metabolic data clearly demonstrated that the AE-PS or alendronate exerted protective effects on the maintenance of calcium homeostasis by regulating calcium absorption in the kidney and the duodenum of the mice with DXM-induced GIOP. Moreover, the regulatory effect of the AE-PS on renal CaSR expression was examined. The downregulation of CaSR in the kidney by the AE-PS may provide a better explanation for its effective inhibition of the elevated excretion of urinary calcium in mice with GIOP shown by the present study. CaSR serves as a sensor of the extracellular calcium level in different tissues and plays a key role in regulating the of secretion of calciotropic hormones, such as PTH and calcitonin (37).

Taken together, the findings of the present study demonstrated that the AE-PS and alendronate succeeded in ameliorating DXM-induced bone loss. The AE-PS and alendronate effectively inhibited the loss of calcium from the urine and ameliorated the histological damage caused to the bone by DXM. The underlying molecular mechanisms, at least partially, involve the regulation of kidney and duodenal calcitropic genes and renal CaSR expression. According to the comparative study, we found that the AE-PS ameliorated trabecular bone loss induced by a disrupted calcium homeostasis due to DXM. In conclusion, these data suggest that the AE-PS may be used as a novel alternative agent for the management of secondary osteoporosis. However, further studies are required in order to determine the precise effect of each constituent of the AE-PS on bone.

\section{References}

1. Zhou DA, Zheng HX, Wang CW, Shi D and Li JJ: Influence of glucocorticoids on the osteogenic differentiation of rat bone marrow-derived mesenchymal stem cells. BMC Musculoskelet Disord 15: 239, 2014.

2. Scudeletti M, Musselli C, Lanza L, Peirano L, Puppo F and Indiveri F: The immunological activity of corticosteroids. Recenti Prog Med 87: 508-515, 1996 (In Italian).

3. Lin H, Wei B, Li G, Zheng J, Sun J, Chu J, Zeng R and Niu Y: Sulforaphane reverses glucocorticoid-induced apoptosis in osteoblastic cells through regulation of the Nrf2 pathway. Drug Des Devel Ther 8: 973-982, 2014.

4. Steinbuch M, Youket TE and Cohen S: Oral glucocorticoid use is associated with an increased risk of fracture. Osteoporos Int 15: 323-328, 2004

5. Van Staa TP, Laan RF, Barton IP, Cohen S, Reid DM and Cooper C: Bone density threshold and other predictors of vertebral fracture in patients receiving oral glucocorticoid therapy. Arthritis Rheum 48: 3224-3229, 2003.

6. Bitto A,Polito F,Burnett B,Levy R,Di Stefano V, Armbruster MA, Marini H, Minutoli L, Altavilla D and Squadrito F: Protective effect of genistein aglycone on the development of osteonecrosis of the femoral head and secondary osteoporosis induced by methylprednisolone in rats. J Endocrinol 201: 321-328, 2009.

7. Reid IR: Glucocorticoid osteoporosis - mechanisms and management. Eur J Endocrinol 137: 209-217, 1997.

8. Capozzi A, Casa SD, Altieri B and Pontecorvi A: Chronic low-dose glucocorticoid inhalatory therapy as a cause of bone loss in a young man: case report. Clin Cases Miner Bone Metab 10: 199-202, 2013.

9. De Vries F, Bracke M, Leufkens HG, Lammers JW, Cooper C and Van Staa TP: Fracture risk with intermittent high-dose oral glucocorticoid therapy. Arthritis Rheum 56: 208-214, 2007.

10. McIlwain HH: Glucocorticoid-induced osteoporosis: Pathogenesis, diagnosis, and management. Prev Med 36: 243-249, 2003

11. Yoon HY, Won YY and Chung YS: Poncirin prevents bone loss in glucocorticoid-induced osteoporosis in vivo and in vitro. J Bone Miner Metab 30: 509-516, 2012.

12. Jahn K, Lara-Castillo N, Brotto L, Mo CL, Johnson ML, Brotto M, Bonewald LF: Skeletal muscle secreted factors prevent glucocorticoid-induced osteocyte apoptosis through activation of beta-catenin. Eur Cell Mater 24: 197-210, 2012. 
13. Ma X, Zhang X, Jia Y, Zu S, Han S, Xiao D, Sun H and Wang Y: Dexamethasone induces osteogenesis via regulation of hedgehog signalling molecules in rat mesenchymal stem cells. Int Orthop 37: 1399-1404, 2013.

14. Duzen O, Erkoc R, Begenik H, Soyoral YU and Aldemir MN: The course of hypercalciuria and related markers of bone metabolism parameters associated with corticosteroid treatment. Ren Fail 34: 338-342, 2012.

15. Kinoshita Y, Masuoka K, Miyakoshi S, Taniguchi S and Takeuchi Y: Vitamin D insufficiency underlies unexpected hypocalcemia following high dose glucocorticoid therapy. Bone 42 : 226-228, 2008

16. Mori-Okamoto J, Otawara-Hamamoto $\mathrm{Y}$, Yamato $\mathrm{H}$ and Yoshimura H: Pomegranate extract improves a depressive state and bone properties in menopausal syndrome model ovariectomized mice. J Ethnopharmacol 92: 93-101, 2004.

17. Saravani M, Kazemi Mehrjerdi H, Mirshahi A and Afkhami Goli A: Protective effects of pomegranate seed oil on ovariectomized rats as a model of postmenopausal osteoporosis: a multi-detector computed tomography evaluation. Vet Res Forum 5: 263-267, 2014.

18. Tzulker R, Glazer I, Bar-Ilan I, Holland D, Aviram M and Amir R: Antioxidant activity, polyphenol content, and related compounds in different fruit juices and homogenates prepared from 29 different pomegranate accessions. J Agric Food Chem 55: 9559-9570, 2007.

19. Hasnaoui N, Wathelet B and Jiménez-Araujo A: Valorization of pomegranate peel from 12 cultivars: dietary fibre composition, antioxidant capacity and functional properties. Food Chem 160: 196-203, 2014.

20. Kim ND, Mehta R, Yu W, Neeman I, Livney T, Amichay A, Poirier D, Nicholls P, Kirby A, Jiang W, et al: Chemopreventive and adjuvant therapeutic potential of pomegranate (Punica granatum) for human breast cancer. Breast Cancer Res Treat 71: 203-217, 2002

21. Spilmont M, Léotoing L, Davicco MJ, Lebecque P, Mercier S, Miot-Noirault E, Pilet P, Rios L, Wittrant $Y$ and Coxam V: Pomegranate seed oil prevents bone loss in a mice model of osteoporosis, through osteoblastic stimulation, osteoclastic inhibition and decreased inflammatory status. J Nutr Biochem 24: $1840-1848,2013$

22. Lou Q-Q, Zhang Y-F, Zhou Z, Shi YL, Ge YN, Ren DK, Xu HM Zhao YX, Wei WJ and Qin ZF: Effects of perfluorooctanesulfonate and perfluorobutanesulfonate on the growth and sexual development of Xenopus laevis. Ecotoxicology 22: 1133-1144, 2013.

23. Shuid AN and Mohamed IN: Pomegranate use to attenuate bone loss in major musculoskeletal diseases: an evidence-based review. Curr Drug Targets 14: 1565-1578, 2013.

24. Spilmont M, Léotoing L, Davicco MJ, Lebecque P, Mercier S, Miot-Noirault E, Pilet P, Rios L, Wittrant Y and Coxam V: Pomegranate and its derivatives can improve bone health through decreased inflammation and oxidative stress in an animal model of postmenopausal osteoporosis. Eur J Nutr 53: 1155-1164, 2014.
25. Mok CC, Ho LY and Ma KM: Switching of oral bisphosphonates to denosumab in chronic glucocorticoid users: a 12-month randomized controlled trial. Bone 75: 222-228, 2015.

26. Bitto A, Burnett BP, Polito F, Levy RM, Marini H, Di Stefano V, Irrera N, Armbruster MA, Minutoli L, Altavilla D and Squadrito F: Genistein aglycone reverses glucocorticoid-induced osteoporosis and increases bone breaking strength in rats: a comparative study with alendronate. Br J Pharmacol 156 $1287-1295,2009$.

27. Lin H, Gao X, Chen G, Sun J, Chu J, Jing K, Li P, Zeng R and Wei B: Indole-3-carbinol as inhibitors of glucocorticoid-induced apoptosis in osteoblastic cells through blocking ROS-mediated Nrf2 pathway. Biochem Biophys Res Commun 460: 422-427, 2015.

28. Jia D, O'Brien CA, Stewart SA, Manolagas SC and Weinstein RS: Glucocorticoids act directly on osteoclasts to increase their life span and reduce bone density. Endocrinology 147: 5592-5599, 2006.

29. Yongtao Z, Kunzheng W, Jingjing Z, Hu S, Jianqiang K, Ruiyu L and Chunsheng W: Glucocorticoids activate the local renin-angiotensin system in bone: possible mechanism for glucocorticoid-induced osteoporosis. Endocrine 47: 598-608, 2014.

30. Tamura Y, Kawao N, Yano M, Okada K, Okumoto K, Chiba Y, Matsuo $\mathrm{O}$ and Kaji $\mathrm{H}$ : Role of plasminogen activator inhibitor-1 in glucocorticoid-induced diabetes and osteopenia in mice. Diabetes 64: 2194-2206, 2014.

31. Zhang Y, Diao TY, Wang L, Che CT and Wong MS: Protective effects of water fraction of Fructus Ligustri Lucidi extract against hypercalciuria and trabecular bone deterioration in experimentally type 1 diabetic mice. J Ethnopharmacol $158 \mathrm{Pt}$ A: 239-245, 2014

32. Sonntag $\mathbf{J}$ and Gaude M: Effect of dexamethasone and spironolactone therapy in calcium and phosphate homeostasis in premature infants with a birth weight under 1,500 g. Klin Padiatr 210: 354-357, 1998 (In German).

33. Lin YJ, Yeh TF, Lin HC, Wu JM, Lin CH and Yu CY: Effects of early postnatal dexamethasone therapy on calcium homeostasis and bone growth in preterm infants with respiratory distress syndrome. Acta Paediatr 87: 1061-1065, 1998.

34. Hoenderop JG, Nilius B and Bindels RJ: Calcium absorption across epithelia. Physiol Rev 85: 373-422, 2005.

35. Alexander RT, Rievaj J and Dimke H: Paracellular calcium transport across renal and intestinal epithelia. Biochem Cell Biol 92: 467-480, 2014.

36. Nijenhuis T, Hoenderop JG and Bindels RJ: TRPV5 and TRPV6 in $\mathrm{Ca}^{2+}$ (re)absorption: regulating $\mathrm{Ca}^{2+}$ entry at the gate. Pflugers Arch 451: 181-192, 2005.

37. Rainone F, Arcidiacono T, Terranegra A, Aloia A, Dogliotti E, Mingione A, Spotti D, Francucci CM, Soldati L and Vezzoli G: Calcium sensing receptor and renal mineral ion transport. J Endocrinol Invest 34 (Suppl): 8-12, 2011. 